\title{
Vigilancia, control social y agencia política del activismo por los derechos humanos ante la llegada de la Comisión Interamericana de Derechos Humanos (Argentina, 1979)
}

\author{
Human Rights Activism's Political Agency, State Surveillance, and Social \\ Control during the Inter-American Commission on Human Rights visit
} (Argentina, 1979)

Débora D’Antonio*

\begin{abstract}
Resumen
En este artículo reconstruyo los distintos tipos de acciones desplegadas por las organizaciones y los activistas por los derechos humanos en territorio bonaerense en el año 1979, antes y durante la visita a la Argentina de la Comisión Interamericana por los Derechos Humanos (CIDH). Tales iniciativas son reconstruidas fundamentalmente por medio de los partes de la Dirección de Inteligencia de la Policía de la Provincia de Buenos Aires (DIPBA) y de otras fuerzas de seguridad. Al mismo tiempo exploro cómo el tejido de estas relaciones y las denuncias practicadas desde los comienzos de la dictadura militar se dinamizaron y fortalecieron durante esta coyuntura.
\end{abstract}

Palabras clave: derechos humanos, $\mathrm{CIDH}$, inteligencia estatal, activismo

\begin{abstract}
In this article I analyze the actions that Human Rights organizations carried out in the Buenos Aires area before and during the 1979 Interamerican Commission on Human Rights (IACHR) visit, as veedor agency, to Argentina. Such endeavors were reconstructed fundamentally through the analysis of intelligence reports by both the Dirección de Inteligencia de la Policía de la Provincia de Buenos Aires (DIPBA) Buenos Aires Province Police Intelligence Direction- as well as by other security forces agencies. At the same time, I explore how these relationships and the actual complaints intertwined since the very beginning of military dictatorship gained dynamism and strengthened during this particular political situation.
\end{abstract}

Keywords: human rights, CIDH, activism, intelligence services

Recibido: 7 octubre 2016

Aceptado: 14 diciembre 2016

\footnotetext{
*Argentina. Dra. en Historia. Universidad de Buenos Aires (UBA). Consejo Nacional de Investigaciones Científicas y Técnicas (CONICET). E mail: deboradantonio@hotmail.com
} 


\section{Introducción}

Entre 1976 y 1979 el dominio del último gobierno militar argentino sobre la sociedad civil parecía ser absoluto. Sin embargo cumplido ese período se abrió un proceso de erosión de los atributos del poder militar centrados en el régimen de terror. Esto posibilitó una resistencia cada vez más pública de los sectores afectados de modo directo por la represión.

Varios factores influyeron para que esto sucediera. Por un lado, el presidente de los EE. UU, James Carter, dio un giro en la política exterior en materia de derechos humanos, restringiendo las cruzadas anticomunistas y el apoyo que sus predecesores le habían procurado a las dictaduras del Caribe y de la región sur. Inicialmente los militares argentinos creyeron que esta era una mera retórica pero cuando Carter los presionó económica, política y diplomáticamente por las violaciones a los derechos humanos que le informaba su propia embajada en Buenos Aires fue tachado de comunista. Por otro lado fueron clave las denuncias que llevaron adelante los exiliados y expulsados del Cono Sur al continente europeo, a los Estados Unidos o a otros países de Latinoamérica porque interesaron y sensibilizaron sobre estos temas a importantes sectores de la opinión pública a nivel mundial (Yankelevich, 2004; Yankelevich y Jensen, 2007; Franco, 2008; Green, 2009; Jensen, 2010; Ayala, 2014). También fue muy significativa la labor de investigación que llevó a cabo Amnesty Internacional luego de visitar la Argentina a fines de 1976. La organización pudo corroborar denuncias de secuestros, torturas, asesinatos, maltrato a los prisioneros políticos e inseguridad para los refugiados latinoamericanos. Sus señalamientos críticos concluyeron con la puesta a disposición de la primera lista pública de personas desaparecidas. ${ }^{2}$ Por su parte las visitas que la Cruz Roja Internacional realizó en 1976, 1977 y 1978 a las cárceles federales y provinciales redundaron en un registro meticuloso de la cantidad de personas presas por razones políticas en esos primeros años de gobierno. ${ }^{3}$ Junto a estas tensiones maduraban otras como la disconformidad en el seno de la clase trabajadora por la desigual redistribución de la renta y el deterioro abrupto que había tenido en sus condiciones de vida.

En este marco fue impulsada la visita de la Comisión Interamericana por los Derechos Humanos (CIDH) como resultado de una serie de negociaciones pacientes que desarrollaron familiares de víctimas de la represión y militantes por los derechos humanos como Augusto Conte, ${ }^{4}$ Emilio Mignone, ${ }^{5}$ Graciela Fernández Meijide ${ }^{6}$ o Simón Lázara ${ }^{7}$

\footnotetext{
${ }^{2}$ Ver Misión de Amnistía Internacional a la República Argentina, 6-15 noviembre de 1976, Anmnesty International Publications, Londres, Inglaterra, 1977.

${ }^{3}$ Ver Imagen Diplomática, http://imagendiplomatica.com/nota.php?n=148.

4 Augusto Conte fue un abogado proveniente de la democracia cristiana y subsecretario en el área de educación del gobierno que derrocó a Perón en 1955. La desaparición de su hijo del Servicio Militar Obligatorio durante la última dictadura militar produjo en él un cambio de perspectiva sobre las FF. AA. A partir de ese momento comenzó a participar con mucho compromiso de la labor de los organismos defensores de los derechos humanos y a interesarse en la comprensión del funcionamiento del Estado Terrorista.

${ }^{5}$ Emilio Mignone fue funcionario del gobierno de facto del general Juan Carlos Onganía y la desaparición de su hija lo llevó a convertirse en miembro clave del movimiento por los derechos humanos en Argentina. Ver http://www.pagina12.com.ar/especiales/30anios/momentos_clave-horacio_verbitsky.html.
} 
En septiembre de 1979 finalmente arribó la CIDH, un órgano autónomo y consultivo de la OEA, que junto a la Corte Interamericana de Derechos Humanos conforman el sistema interamericano de protección a los derechos humanos en todo el continente. Su objetivo era investigar las más de 5580 denuncias recibidas sobre desaparición de personas, tormentos y vejaciones múltiples. Desde ese momento la oposición fuertemente centrada en el movimiento de derechos humanos desarrolló un accionar político y una resistencia cada vez más abierta contra estas prácticas. Si hasta entonces el gobierno militar había logrado dominar a la sociedad civil y había propiciado el ocultamiento de los crímenes de Estado a partir de esa coyuntura la balanza se inclinaba en favor de su visibilización. ${ }^{8}$

El juego entre los aspectos ocultos y los visibles de la represión tuvo por objetivo en los primeros años del régimen no afectar la legitimidad del Estado. Pero con la llegada de la CIDH esta ecuación se alteró de manera ineludible, tornándose cada vez más evidente lo que hasta allí se había procurado ocultar. No resulta esta una interpretación causal del rol de este arribo sino un análisis del proceso social y político que se expresó en la decisión de la Organización de Estados Americanos (OEA) de enviar a esta Comisión y de las posibilidades que esta visita le ofreció a las fuerzas sociales locales antidictatoriales. El mero desempeño del organismo internacional sin el accionar de los integrantes del movimiento por los derechos humanos local y de los familiares de las víctimas de la represión estatal no hubiese provocado la pérdida de legitimidad del gobierno. No fueron incipientes las acciones de este sector pues tenían varios años de desarrollo, sin embargo, la llegada de la CIDH las potenció, por un lado, y animó al movimiento a ocupar nuevos espacios públicos por otro. ${ }^{9}$

\footnotetext{
${ }^{6}$ Graciela Fernández Meijide era una profesora de lengua extranjera que a partir de la desaparición de su hijo se transformó en una activista destacada por los derechos humanos. En 1983 integró la Comisión Nacional sobre la Desaparición de Personas (CONADEP).

7 Simón Lázara fue militante del Partido Socialista Argentino (PSA) y luego pasó a las filas de la Unión Cívica Radical (UCR). Asimismo fue miembro fundador de la Asamblea Permanente por los Derechos Humanos (APDH).

${ }^{8}$ Ver la evolución de la política del Proceso de Reorganización Nacional (PRN) en Canelo, Paula, El proceso en su laberinto. La interna militar de Videla a Bignone, Prometeo, Buenos Aires, 2008.

${ }^{9}$ Aunque las camadas de activistas y familiares por los derechos humanos se fueron renovando al calor de las líneas represivas de los diferentes momentos de los aparatos estatales es importante destacar que desde mediados del siglo XX existieron distintas comisiones que trabajaron en favor de los detenidos políticos. Un ejemplo de ellos es la Comisión de Familiares de Detenidos Políticos y Gremiales (COFADE) que tuvo actuación durante el plan represivo de Conmoción Interna del Estado (CONINTES) creado en 1958 y vigente hasta 1961. Ver Chama, Mauricio, "La defensa de presos políticos a comienzos de los '70: ejercicio profesional, derecho y política", Cuadernos de antropología social, №32, 2010, 195-217. También la amplia actividad de defensa y solidaridad con los presos políticos en los primeros años setenta es otro antecedente clave para la constitución del movimiento de derechos humanos de la Argentina bajo el Terrorismo de Estado. Ver este tema en Eidelman, Ariel, "El PRT-ERP y la lucha por la libertad de los presos políticos, 1971-1973", Sociohistórica, No 25, 2009, 13-39. Ya en 1974 se destacó el trabajo del Servicio de Paz y Justicia (SERPAJ) y en enero de 1975 el de la APDH que reunía a diversos sectores sociales, políticos, intelectuales, sindicales y religiosos. Familiares de detenidos y desaparecidos por razones políticas surgió en enero de 1976 y las Madres de las Plaza de Mayo y las Abuelas comenzaron a organizarse en 1977. Por último en 1979 se conformó el Centro de Estudios legales y Sociales (CELS) con la labor inicial de un núcleo de abogados y familiares.
} 
La hipótesis central de este trabajo es que la oposición centrada en el movimiento de derechos humanos articuló una serie de estrategias fundacionales de lucha contra la represión estatal y un accionar político que se consolidó de allí en adelante, estimulado además por una opinión pública internacional crítica de las violaciones a los derechos humanos. Estas experiencias posibilitaron por otro lado la articulación de una red solidaria amplia que fue percibida por las fuerzas de seguridad como una nueva amenaza para el orden social.

Teniendo en cuenta este particular contexto nacional e internacional, y sobre la base del análisis de la documentación producida por la extinta Dirección de Inteligencia de la Policía de la Provincia de Buenos Aires (DIPBA), que vigilaba, espiaba y controlaba a las fuerzas sociales y políticas, me prepongo en este artículo reconstruir las distintas iniciativas desplegadas por los activistas por los derechos humanos en la coyuntura de la visita de la $\mathrm{CIDH}$ en territorio bonaerense. ${ }^{10} \mathrm{Me}$ he detenido a examinar estos archivos que se encuentran ordenados en la Mesa Delincuente Subversivo (DS) de este fondo documental porque se conserva en él, el carácter de la mirada policial de los años setenta en torno a la militancia por los derechos humanos (Kahan, 2007). ${ }^{11}$ Estos escritos de inteligencia policial ponen en valor de modo indirecto un repertorio de acciones de oposición al régimen que junto a los testimonios ofrecidos en sede judicial y a las memorias de los protagonistas del pasado reciente, permiten reconstruir la agencia política de los sectores nucleados en torno a los derechos humanos.

Distintas son las voces que en el campo historiográfico local, en el marco de un creciente interés por comprender la lógica de funcionamiento de la represión estatal del pasado reciente, se han expresado sobre el valor de los documentos provenientes de los "archivos de la represión”. 12 Ludmila da Silva Catela planteó, por ejemplo, la necesidad

\footnotetext{
${ }^{10}$ El volumen de información completa del archivo que hoy se encuentra en guarda en la Comisión Provincial por la Memoria en la ciudad de La Plata (pcia. de Buenos Aires) equivale a 4 millones de folios o a 336 metros lineales de papel. El fondo documental está organizado en diferentes mesas a partir de los datos que contienen cada uno de legajos personales o de organizaciones políticas, sindicales, sociales, culturales o religiosas. Si bien se encuentran en guarda unos pocos documentos de los años treinta del siglo XX, el grueso de la información data de fines de los años cincuenta en adelante. Ver Kahan, Emmanuel Nicolás, “¿Qué represión, qué memoria? El archivo de la represión de la DIPBA: Problemas y perspectivas”, Question, vol. No 1, No. 16, 2010, 1-10. http://perio.unlp.edu.ar/ojs/index.php/question/article/view/459

${ }^{11}$ En la mesa DS se registraban las actividades calificadas de "subversivas" (organizaciones armadas, registros de sucesos relacionados con robos y tenencia de armas y/o explosivos, atentados y acciones varias disruptivas).

${ }^{12}$ Elizabeth Jelin ha denominado "archivos de la represión" a aquellos que tienen su origen en la actividad de las instituciones represivas del Estado, en las denuncias recogidas por las organizaciones defensoras de los derechos humanos o en las Comisiones por la Verdad como la CONADEP u otros repositorios que reúnen información dispersa sobre los años del terrorismo estatal. Ver Jelin, Elizabeth, "Introducción. Gestión política, gestión administrativa y gestión histórica: ocultamientos y descubrimientos de los archivos de la represión”, Da Silva Catela, Ludmila y Jelin, Elizabeth (comps.) Los archivos de la represión: documentos, memoria y verdad, Madrid, Siglo Veintiuno, 2002, 1-12. Ver también, Barreneche, Osvaldo, "Manejo metodológico de las fuentes documentales y los archivos policiales. El caso de la Policía de la Provincia de Buenos Aires", Revista Electrónica de Fuentes y Archivos del Centro de Estudios Históricos "Prof. Carlos S. A. Segreti", No 1, 2010, 1-17 donde demuestra que las fuentes policiales no tienen un carácter monolítico y que por el contrario presentan matices y enfoques diferentes. También ver González Quintana, Antonio, "Los
} 
de establecer controles epistemológicos sobre estos materiales atendiendo a las condiciones de producción y a las lógicas clasificatorias con las que los distintos organismos de seguridad produjeron la documentación. La precaución misma hace ostensible el carácter arbitrario de este acervo en tanto es un producto social que surge como resultado del accionar regular de un aparato represivo de un estado militar, y que a la vez se enmarca en las disputas públicas sobre la memoria social de ese mismo pasado reciente (da Silva Catela, 2007). Algunos otros investigadores matizaron la fidelidad de este reservorio al señalar obstáculos a la hora de conocer con certeza quien produjo y bajo qué procedimientos clasificó esta documentación, justamente por el carácter secreto de la misma (Ghigliani, 2012). Finalmente se ha relativizado el grado de penetración y de eficacia de los agentes de inteligencia en la sociedad civil por existir sospechas de que muchos informes eran confeccionados a partir de relatos proporcionados por terceras personas. En relación a este punto vale la pena señalar que la misma DIPBA controlaba la información por medio de una codificación que jerarquizaba el grado de veracidad y de confiabilidad de los datos producidos por los distintos aparatos de inteligencia. ${ }^{13}$

Teniendo en cuenta estos recaudos metodológicos en un primer apartado contextualizo y abordo algunos aspectos del funcionamiento de la DIPBA con el propósito de poner en contexto la lógica burocrática de la institución en el largo plazo así como las especificidades surgidas bajo el terrorismo de Estado y la relevancia de la policía como fuerza represiva y sus vínculos con las FF.AA. En un segundo apartado me detengo en las formas de vigilancia que esta institución policial ensayó sobre el frente de activistas por los derechos humanos a la par que examino la agenda de trabajo que este sector propuso con el propósito de visibilizar en esta coyuntura tan particular, la represión que el Estado ejerció sobre amplias capas de la sociedad civil. Finalmente cierro el artículo ponderando algunas ideas.

\section{La DIPBA}

Para entender los alcances de la vigilancia, control, persecución y represión que caracterizaron a esta institución policial resulta necesario realizar una breve consideración sobre su historia. Esta agencia de inteligencia estatal bonaerense fue establecida en el año 1956 en el marco de la proscripción y persecución al peronismo, de la flamante Doctrina de Seguridad Nacional y de la creación o jerarquización de otros aparatos represivos del Estado. La DIPBA se mantuvo activa como agencia de inteligencia, aunque con diferentes nombres según los vaivenes políticos e institucionales hasta su disolución en el año 1998. Se inscribió de este modo en un continuum de prácticas, normativas y modos de representar y organizar los registros del espionaje político e ideológico. ${ }^{14}$ Lila Caimari ha explicado que

archivos de la represión: balance y perspectivas", Comma, Revista Internacional de Archivos, № 2, 2004, 5974.

${ }^{13}$ Ver sobre la veracidad de la documentación http://www.comisionporlamemoria.org/timerman/

${ }^{14}$ Ver la relación entre continuidades y rupturas en los aparatos represivos del Estado en: Águila, Gabriela, "Las tramas represivas: continuidades y discontinuidades en un estudio de caso. La Dirección General de Informaciones de la Provincia de Santa Fe, 1966-1991", Sociohistórica, No 31, 2013, 1-26; Franco, Marina, "En busca del eslabón perdido: reflexiones sobre la represión estatal de la última dictadura militar", Revista Estudios, $N^{\mathrm{o}} 25,2011,31-45$ y D’Antonio, Débora y Eidelman, Ariel, “El sistema penitenciario y los presos (cc) (O) 
ya en los años treinta la institución policial estaba acostumbrada a espiar a los enemigos políticos (Caimari, 2009) y Laura Kalmanowiecki, que reconstruyó el sistema de control y persecución policial a los opositores políticos surgidos tras el golpe del general José Félix Uriburu, destacó la transferencia de saberes que las distintas divisiones de inteligencia policial le proporcionaron tempranamente al Ejército Nacional (Kalmanowiecki, 2000). ${ }^{15}$ Uno y otro señalamiento revelan que la Policía para fines de los años setenta, contaba con décadas de experiencia en el armado de arquetipos y prácticas de vigilancia, control y persecución de aquellos sindicados como enemigos políticos: un legado que heredaría la DIPBA al momento de su creación. Sin embargo, a partir de la segunda mitad del siglo XX, cuando los sucesivos golpes de Estado llevaron a que las instituciones policiales fueron "colonizadas" en los escalafones jerárquicos por oficiales superiores de las FF. AA, favoreciendo un modelo militarizado de la misma, esta autonomía debe ser matizada. ${ }^{16}$

Para la coyuntura específica en la que este artículo se detiene cabe destacar además que las FF. AA idearon un mecanismo al que denominaron "Comunidad Informativa" que se basaba en términos formales en la mutua cooperación interinstitucional de las fuerzas de seguridad y de las fuerzas armadas siendo en términos reales estas últimas las que coordinaban y regulaban políticamente la producción e intercambio de información y las acciones de espionaje de los diferentes servicios de inteligencia. La "Comunidad Informativa" se convirtió en una pieza estratégica de la represión del Estado terrorista y en ella tuvieron lugar: el Servicio de Inteligencia de Estado (SIDE), el Batallón de Inteligencia 601, cabeza del Servicio de Inteligencia del Ejército (SIE), el Servicio de Inteligencia Naval (SIN), el Servicio de Inteligencia de Gendarmería Nacional (SIGN), el Servicio de Inteligencia de Prefectura Naval Argentina (SIPNA), el Servicio de Inteligencia Aeronáutica (SIA), el de Seguridad Federal (SF) y, también, la DIPBA. En la documentación consultada la estructura orgánica formalizada y reglamentada de esta "comunidad" adquiere materialidad en la elevación profusa de los informes del personal policial directamente a las autoridades militares del Comando de Zona o del Destacamento de Inteligencia correspondiente a la misma. Los acuerdos de reciprocidad, por su parte, requerían que la policía "liberase" la zona o "prestase" personal a los grupos operativos de las FF. AA para la concreción de los secuestros clandestinos. Y a la vez las FF. AA le solicitaban a la DIPBA acciones de seguimiento como "averiguaciones encubiertas en domicilios de personas detenidas a disposición del PEN, chequeos de domicilio de eventuales blancos en el ámbito de su jurisdicción, etc." (Olmo, 2002: 189). Para enero de 1977 la DIPBA elevó su rango a Dirección General de Inteligencia con el propósito de garantizar eficacia operativa en la vigilancia y el control. Las instituciones policiales que tuvieron un larguísimo proceso de profesionalización a mediados de los años setenta fueron subsumidas en las decisiones más generales de las FF. AA, lo que no niega que la Policía

políticos durante la configuración de una nueva estrategia represiva del Estado argentino (1966-1976)", Revista Iberoamericana, vol. X, No 40, 2010, 93-111.

${ }^{15} \mathrm{Sin}$ entrar en detalles no puede soslayarse la ley 13.234 o de "Organización de la nación para tiempos de guerra" elaborada en 1948 durante el peronismo y puesta en vigencia algunos años después donde se coordinan todos los factores de poder nacional en apoyo al factor militar.

${ }^{16}$ Ver este tema en Sozzo, Máximo, (dir.) Policía, violencia, democracia. Ensayos sociológicos. Ediciones UNL, Universidad Nacional del Litoral, Santa Fe, 2005. 
haya tenido afinidad organizacional e ideológica con la misma. ${ }^{17}$ Es por este motivo que en los archivos de la agencia de inteligencia bonaerense no sólo se encuentran sus propios documentos sino aquellos producidos y distribuidos por otras fuerzas integrantes de la "Comunidad Informativa", dejando en claro la conexión entre los distintos organismos de inteligencia y de represión a nivel provincial y nacional.

El trabajo de vigilancia y registro de las diversas seccionales de la DIPBA no remitía el mismo volumen ni la misma calidad puesto que la información variaba según las coyunturas políticas y según las seccionales y direcciones a cargo. Este se desarrollaba en base a diferentes mecanismos. Por un lado existía personal de inteligencia que se infiltraba en los ámbitos que le eran asignados para su investigación como puede ser una asamblea obrera, una marcha estudiantil o una reunión de militantes de organismos por los derechos humanos. El agente realizaba un informe de primera mano que muchas veces era minucioso y con vívidos detalles y descripciones. Estos escritos se completaban con otro tipo de materiales recolectados en los distintos ámbitos observados como comunicados, revistas, folletos, panfletos, cartas, originales manuscritos, versiones foto-duplicadas de volantes, apuntes, diarios o fotografías. ${ }^{18}$ Otros informes por el contrario no eran producidos de primera mano y se confeccionaban exclusivamente por medio de una colección de noticias de publicaciones periódicas que registraba la actividad de los partidos políticos, las organizaciones político-militares, de organismos de gobierno, de asociaciones vecinales o de grupos religiosos, entre otros, o por la información ofrecida, como ya se dijo, por terceras personas, testigo de los hechos investigados. Algunos agentes llevaban el registro de denuncias que aparecían en los medios públicos de desaparición de personas, de atentados, de enfrentamientos, de prisioneros políticos, de asesinatos, de la actividad de los familiares de detenidos, de protestas, huelgas o presentaciones ante el poder judicial. De conjunto si algunos informes presentaban formas rutinarias burocráticas otros surgían de líneas de investigación expresas.

Sobre la base de los paradigmas represivos de la institución policial, los agentes realizaban sus tareas con la lente del imaginario construido sobre el enemigo político que se plasmó, según la época, en clasificaciones cambiantes como las del delincuente político, el delincuente social o del comunista genérico al delincuente subversivo y más tarde, al delincuente terrorista. ${ }^{19}$

\footnotetext{
${ }^{17}$ Ver las diferencias de roles entre fuerzas policiales y militares en Waldamnn, Peter, "Represión Estatal y Paraestatal en Latinoamérica”, Revista América Latina Hoy, 2 época, N ${ }^{\circ}$ 19, junio, 1995, 21-28.

${ }^{18}$ Ver la cuestión de la clasificación en Basualdo, Victoria, "Introducción", Colección 8: Petroquímica Sudamericana. Hilandería Olmos. Mafissa (1963-1991), Comisión Provincial por la Memoria, CD-ROM, 2009.

${ }^{19}$ Ver este tema en: Funes, Patricia, "Secretos, confidenciales y reservados. Los registros de las dictaduras en la Argentina. El Archivo de la Dirección de Inteligencia de la Policía de la provincia de Buenos Aires", Quiroga, Hugo y Tcach, César (comps.), Argentina 1976-2006. Entre la sombra de la dictadura y el futuro de la democracia. HomoSapiens ediciones, Rosario, 2006, 203-4 y la cuestión del enemigo interno en el marco de la Guerra fría en Manzano, Valeria, "Sex, Gender and the Making of the 'Enemy Within' in Cold War Argentina", Journal of Latin American Studies, vol. No 47, N 1, 2014, 1-29.
} 


\section{Actividad de inteligencia y militancia por los derechos humanos}

En febrero de 1979 el Batallón 601, cabeza del Servicio de Inteligencia del Ejército, ${ }^{20}$ distribuyó entre las agencias SIA, SIN, SIPNA, DIPBA, SF, SIDE, GT 2, GT 3, GT 4 y GT $5^{21}$ un documento que alertaba sobre la organización de los familiares de víctimas de la represión ante la futura llegada de la CIDH. En él se expresaba que:

[....] se tuvo conocimiento que los familiares de presos y desaparecidos tienen estructurado un plan que llevarán a cabo con motivo del arribo de la Comisión por los Derechos Humanos. El plan consistiría basado en la presentación de distintas pruebas que obrarían en poder de ellos y que le permita a la referida Comisión llevar una investigación en forma positiva. $^{22}$

El Batallón 601 comunicaba a las distintas agencias de inteligencia que el norte del plan de los familiares y de los organismos consistía en reunir pruebas suficientes para comprender qué ocurrió y qué destino tuvo cada persona desaparecida. El informe manifestaba una preocupación por este grupo que se mostraba lúcido para la confección y fundamentación de las denuncias. Una descripción coincidente con los viajes que realizaban algunos miembros de los organismos de derechos humanos a la OEA en Estados Unidos con el propósito de conseguir asesoramiento legal. ${ }^{23}$

El informe de inteligencia militar detallaba que los integrantes de la Asamblea Permanente por los Derechos Humanos (APDH) se iban a concentrar en:

[....]la recopilación de antecedentes, sobre personas desaparecidas, detenidas, secuestradas, que han sido objeto de apremios, etc., los que proporcionados por las propias víctimas o por sus familiares quedan instrumentalizados en actas labradas ante escribanos públicos, con lo que adquieren un valor testimonial de envergadura. En dichos documentos no sólo se consignan los nombres de los 'damnificados' sino que además todas las circunstancias que rodearon cada episodio según fueran sus características poniéndose especial énfasis en detalles que puedan tener alguna significación, marcas, modelos, color y patentes de vehículos

\footnotetext{
${ }^{20}$ En los años del Proceso de Reorganización Nacional el Batallón 601 respondía al Estado Mayor General del Ejercito y tuvo por objetivo específico la inteligencia sobre agrupamientos políticos caracterizados como "subversivos" así como infiltraciones y detenciones ilegales de sus integrantes. Hacia 1979 el batallón "exportó" su tecnología a países como Honduras o Guatemala, quienes a la vez contribuyeron con la formación de los contras nicaragüenses en pleno proceso revolucionario.

${ }^{21}$ Los GT o grupos de tareas estaban conformados por miembros de las diversas FF. AA y cuerpos de seguridad del Estado. El GT1 y GT2 (dependía del EA), GT3 (dependía del SIN), GT4 (dependía del SIA) y GT5 (dependía de la SIDE). http://www.saij.gob.ar/docs-f/ediciones/libros/Batallon_inteligencia_601.pdf

${ }^{22}$ Fondo DIPBA, Mesa DS, Carpeta Varios, Legajo 134227. Asunto: "Plan de los familiares de los presos y desaparecidos ante la Asamblea Permanente por los Derechos Humanos”, del Batallón de Inteligencia 601 para SIA, SIN, SIPNA, DIPBA, S FED, DIGN, SIDE, GT 2, GT 3, GT 4 y GT 5. s/d.

${ }^{23}$ Ver "6 de septiembre de 1979. La CIDH llegó a Buenos Aires", Página 12, 29 de agosto de 1999.
} 
intervinientes en procedimientos, uniformes de personal interviniente, nombres que puedan haberse oído y/o proporcionado de dichas personas, identificación de lugares de detención, nombres del personal que haya atendido a posteriori los reclamos de los familiares de las víctimas, expresiones por ellos mismos vertidas, etc. ${ }^{24}$

El eje para estos activistas era reunir denuncias muy bien fundamentadas por medio de testigos que recordasen detalles fehacientes de los operativos de secuestro como podía ser la fisonomía, nombres o apodos de los integrantes de las fuerzas militares y de seguridad o la chapa de los vehículos si la tuviesen. Fue por entonces que se logró unificar con la colaboración de organismos internacionales defensores de los derechos humanos los listados de personas desaparecidas, por un lado, y los listados de personas detenidas por razones políticas en el sistema penitenciario, por otro. Un aspecto clave pues hasta ese momento se contaba solamente con informaciones parciales "ofrecidas" por el ministerio del Interior o publicadas por diarios nacionales o provinciales que muchas veces se superponían y por lo tanto parecían poco certeras. El informe de inteligencia destacaba además que la APDH se posicionaría como anfitriona de los miembros de la CIDH, disputándole ese rol al gobierno. ${ }^{25}$

Otra delegación de la DIPBA de la localidad de Tigre por su parte suscribía que en su región tenía también particular relevancia la actividad de la APDH. Se aseveraba que esta organización le debía su existencia al estímulo que le diera la Liga Argentina por los Derechos del Hombre (LADH) caracterizada como cooptada por el comunismo nativo:

[....] que el accionar de esta asamblea, es semejante al de la $\mathrm{LADH}$, por su pública y notoria relación con el PC. Se aprecia que tendría la finalidad de reemplazarla, por estar esta última desgastada por su accionar político. ${ }^{26}$

La LADH existía desde mediados de los años treinta y había desarrollado una considerable experiencia asociada a la asistencia a los presos políticos y a la resistencia a las distintas embestidas de la represión policial y militar. Desde el punto de vista estatutario la LADH era independiente de los partidos políticos; sin embargo, siguiendo a Natalia Casola en este punto, no puede eludirse que el Partido Comunista argentino apoyó todas las iniciativas organizacionales que contribuyesen a combatir el aislamiento de la izquierda y que tenía su origen en la política de frentes amplios definidos por la Kominform (Casola, 2010). ${ }^{27}$

\footnotetext{
${ }^{24}$ Fondo DIPBA, Mesa DS, Carpeta Varios, Legajo 134227. Asunto: "Plan de los familiares de los presos y desaparecidos ante la Comisión Permanente por los Derechos Humanos", del Batallón de Inteligencia 601 para SIA, SIN, SIPNA, DIPBA, SF, DIGN, SIDE, GT 2, GT 3, GT 4 y GT 5. s/d.

${ }^{25}$ Fondo DIPBA, Mesa DS, Carpeta Varios, Legajo 134.227. Asunto, Mensaje N. ${ }^{\circ}$ 07013. de Batallón de Inteligencia 601, marzo de 1979.

${ }^{26}$ Fondo DIPBA, Mesa DS, Carpeta Varios, Legajo 134.227. Asunto: Memo del Jefe Delegación DGIPBA Tigre para información del señor Director General Inteligencia, La Plata., 12 de febrero de 1979.

${ }^{27}$ Esta era la oficina que bajo la égida de la URSS promovía el intercambio de información y de experiencias entre los partidos comunistas del mundo.
} 
La APDH había surgido para dar una respuesta institucional específica a los "más de cuatro mil presos políticos y sociales que sufren privaciones en las cárceles, donde se encuentran ilegalmente detenidos". ${ }^{28}$ Se advertía que este núcleo de activistas había reunido alrededor de 5000 testimonios por medio de una campaña sostenida en la acumulación de pruebas contra las acciones del Estado. Sus miembros más activos publicitaron esta actividad con el fin de acompañar la entrega de la documentación por medio de una gran movilización a la Plaza de Mayo coincidiendo con la presencia de la comisión investigadora. El objetivo era crear mecanismos de visibilización y de solidaridad entre los distintos sectores sociales. ${ }^{29}$ En el informe se describía también que luego de cada reunión los miembros de la APDH repartían panfletos entre los asistentes con modelos de hábeas corpus e instrucciones de cómo debían ser completados así como un listado de direcciones útiles para poder establecer en los lugares adecuados las denuncias sobre desaparición de personas. El objetivo era estimular conjuntamente las demandas en los ámbitos judiciales, inscribiendo distintos precedentes. El informe volvía a remitir a las actividades llevadas a cabo por la LADH y explicaba que en una reunión donde estuvieron presentes los miembros de Amnesty International se definió un plan para desarrollar una protesta pública en favor de las presas y los presos políticos. El mismo incluiría una concentración frente a la Casa de Gobierno (Poder Ejecutivo Nacional; la concurrencia al Palacio de Tribunales (Poder Judicial) y finalmente la asistencia a una misa vespertina en la Catedral Metropolitana de la ciudad de Buenos Aires.

En otro documento se alertaba que la LADH había sido el organismo que planeó la confección de afiches con la proclama de la "Declaración Universal de los Derechos del Hombre y del Ciudadano" y que se haría una pegatina en la vía pública al momento del arribo de la Comisión al país. ${ }^{30}$ Todas estas acciones serían fortalecidas con la presencia de periodistas argentinos y extranjeros invitados a fin de darle publicidad a los reclamos. ${ }^{31}$ Otros documentos destacaban las reuniones que familiares cercanos a la LADH tuvieron con distintos sacerdotes a fin de pudieran interceder en favor de la vida de sus seres queridos. $^{32}$ Casola sostiene que fue la LADH -más que la APDH- donde el Partido Comunista tuvo una participación en proporciones similares a la del resto de los partidos políticos y que fue este grupo el que organizó a los familiares después del golpe de Estado (Casola, 2010). Como ya se ha señalado, la LADH se destacaba por contar con una extensa trayectoria y experiencia en materia de derechos humanos a diferencia de la $\mathrm{ADPH}$ que era una agrupación de creación más reciente. Tal vez por este motivo fue

\footnotetext{
${ }^{28}$ Fondo DIPBA, Mesa DS, Carpeta Varios, Legajo 134.227. Asunto: Memo del Jefe Delegación DGIPBA Tigre para información del señor Director General Inteligencia, La Plata., 12 de febrero de 1979.

29 También el jefe de la regional Morón conforme a lo que se ha ordenado informa que casi todos los familiares de las personas que se hallan desaparecidas o que están presas canalizan sus inquietudes a través de la APDH. Fondo DIPBA, Mesa DS, Carpeta Varios, Legajo 134.227. Asunto, Memorando del Jefe de la Seccional Regional DGIPBA No 1 de Morón al Señor Director General de Icía (inteligencia militar de aquí en adelante), La Plata, 6 de febrero de 1979.

${ }^{30}$ Fondo DIPBA, Mesa DS, Carpeta Varios, Legajo 134.227. Asunto, Memorando del Jefe de la delegación DGIPBA Capital Federal con destino al Señor Director General de Icía., La Plata, 23 de mayo de 1979.

${ }^{31}$ Ídem.

${ }^{32}$ Fondo DIPBA, Mesa DS, Carpeta Varios, Legajo 13.242. Asunto Memorando producido por DGIPBA para información del Señor Jefe Delegación La Plata de la Policía Federal, 2 de abril de 1979.
} 
percibida por los agentes de inteligencia como una novedad más peligrosa y necesaria de ser controlada, más allá de que el Partido Comunista hasta 1979 no formó parte del arco opositor al gobierno militar.

En febrero de ese año desde la delegación de la DIPBA-Mar del Plata se informaba que de las averiguaciones practicadas en los distintos niveles del Partido Comunista local, se había podido averiguar que, efectivamente, los familiares de los desaparecidos y secuestrados eran:

[...] manipulados por los miembros de esta organización y de sus colaterales de la UMA (Unión de Mujeres Argentinas) y la APDH acompañados en forma encubierta por algunos elementos de la curia local, habrían confeccionado una lista, que entregarían a la CIDH proveyendo a la misma de datos, motivos de las detenciones, nombres y lugares $[\ldots . .]^{34}$

El informe daba también relevancia a los preparativos de estos grupos para el momento del arribo de la CIDH. Como en otras regionales se detallaba que estos tenían previsto desplegar distintas formas de protestas públicas así "como peticionar a la conducción sobre la situación de los presos políticos sin proceso, bajo arresto por las atribuciones del Poder Ejecutivo Nacional y la aclaración sobre la situación de los desaparecidos en estos últimos tres años". 35 El objetivo era que estos temas formasen parte de la agenda política nacional. La recolección, centralización y jerarquización de testimonios dejaba en claro, según los partes de la DIPBA-Mar del Plata, que este proceso había sido estimulado por los activistas del movimiento de derechos humanos y que por lo tanto no tenía un carácter espontáneo. Se señalaba, por ejemplo, que el Centro de Estudios Legales y Sociales (CELS), a través del patrocinio de sus abogados, impulsaba la presentación de escritos de denuncia ante distintas instancias del Poder Judicial. En el mismo informe se ponderaban una serie de registros periodísticos que hacían referencia a un hecho sustantivo de esa coyuntura política como lo fue la presentación colectiva ante la Corte Suprema de Justicia de un reclamo por la desaparición de más de 700 personas. ${ }^{36}$

Los informes hasta aquí consignados muestran respuesta céleres y en concordancia entre sí. Sin embargo a la solicitud de una indagación específica no siempre le correspondía una respuesta equivalente. Incluso algunos pedidos de seguimiento de

\footnotetext{
${ }^{33}$ El Partido Comunista Argentino (PCA) caracterizó en el año 1976 a Jorge Rafael Videla y a Roberto Viola, los dos primeros presidentes de las juntas militares como el ala "blanda" dentro del generalato, con un proyecto político tendiente en el mediano plazo a la realización de una democracia renovada. A diferencia de otros partidos que directamente fueron disueltos, el PCA solo fue suspendido. Ver para la relación de PCA con la dictadura a Casola, Natalia, El PC argentino y la dictadura militar. Militancia, estrategia política y represión estatal, Imago Mundi, Buenos Aires, 2015 y de la misma autora, “iLos comunistas no somos subversivos!". El PC y la dictadura militar argentina (1976-1983)", en Revista Archivos del Movimiento Obrero y la Izquierda, $\mathrm{N}^{\circ} 2,2013,133-156,137-155$.

${ }^{34}$ Fondo DIPBA, Mesa DS, Carpeta Varios, Legajo 134.227. Asunto nota desde la Delegación DGIPBA, Mar del Plata; al Señor Director General de Inteligencia, La Plata, 16 de febrero de 1979.

${ }^{35}$ Ídem.

${ }^{36}$ Ver por ejemplo, "Presentación colectiva ante la Corte, 752 desaparecidos", en Clarín, 14 de septiembre de 1979 citado en İdem.
} 
personas, de actividades o de organizaciones podían presentar resultados negativos. Un ejemplo de esto lo hallamos en la información remitida desde la delegación de la DIPBA de la localidad de San Martín al jefe de inteligencia militar. Allí se dice que:

Diríjome al Señor Director General de Icía. A los efectos de poner en su conocimiento, que, en la jurisdicción no se detectan actuaciones de familiares de presos y desaparecidos, al menos en superficie. Se continúa auscultando. ${ }^{37}$

Si en general la ausencia de acciones de reclamo era interpretada por los agentes de inteligencia como parte de un escaso desarrollo territorial de las organizaciones de derechos humanos también se conjeturaba que la falta de datos podía deberse a la capacidad de camuflaje o de clandestinización de la actividad militante. En todo caso, estas perspectivas no ponían en duda la eficacia de las agencias de inteligencia para vigilar a estos sectores.

Un informe producido por la seccional Bahía Blanca de la DIPBA refirió a la existencia de una "campaña de acción psicológica a favor de los desaparecidos" entre el activismo de derechos humanos consistente en el reparto sistemático entre la "gente común" de distintos tipos de materiales como uno que llevaba por título: "Únase a las Madres de Plaza de Mayo". Puntualmente se alertaba que estos volantes habían sido reproducidos por la técnica de la foto-duplicación, enviados a los gremios obreros de la zona y que, según consta en el matasellos donde se asienta la fecha y el lugar de origen del sobre, y confeccionados en el extranjero. ${ }^{38}$ No es posible confirmar la certeza de estas presunciones ni tampoco asegurar que el agente de inteligencia no estuviese especulando con la existencia de una red articulada entre las Madres de Plaza de Mayo, otros militantes de los organismos de derechos humanos y los exiliados. Tampoco podemos soslayar que esta seccional se hallaba en la principal base de la Armada Argentina en Puerto Belgrano, a solo $24 \mathrm{~km}$ de la ciudad de Bahía Blanca. Esta era una zona particularmente sensible a la temática de la "subversión" por lo que parece bastante probable que "identificasen" más enemigos que en otras seccionales.

Mientras tanto, la unidad de inteligencia de La Plata le informaba al director general de la DIPBA que se había creado una "Comisión de Familiares de Desaparecidos" (COMIFADE). Se explicaba en el informe que el director del diario local El Día había aportado datos sobre este tema provenientes del archivo del matutino. Añadía finalmente que esta documentación sería ofrecida a la $\mathrm{CIDH}$, detallando los nombres de las familias involucradas en tal acción:

Los familiares peticionantes, que utilizarían la información proporcionada, para a su vez entregarle a la Comisión Internacional por los Derechos

\footnotetext{
${ }^{37}$ Fondo DIPBA, Mesa DS, Carpeta Varios, Legajo 134227, Asunto. Memorando del Jefe de la Delegación Regional DGIPBA San Martín al Señor Director General de Icía., La Plata, 6 de febrero de 1979.

${ }^{38}$ Fondo DIPBA, Mesa DS, Carpeta Varios, Legajo 134227. Asunto, Memorando del Jefe de la Seccional Regional DGIPBA Bahía Blanca al Señor Director General de Icía., La Plata, 14 de marzo de 1979 (se adjunta el panfleto).
} 
Humanos, que próximamente visitará nuestro país, serían los siguientes, entre otros: familiares de (...) (PRT) y la madre de (...) (Montoneros), quien, asimismo, habría gestionado ante la Comisión de mención, la investigación del caso donde perdieran la vida sus hijos y desaparecida nieta $[\ldots . ..]{ }^{39}$

A partir de este escrito el Batallón 601 le solicitó a todas las agencias de inteligencia intensificar la vigilancia sobre la COMIFADE con el objetivo de individualizar a sus activistas. Este documento caracterizaba a este agrupamiento como:

[....] un apéndice encubierto de la Liga y a través de la cual ésta ha requerido de distintas organizaciones de frente del comunismo internacional, la ejecución de una serie de diligencias tendientes a implementar una campaña de acción psicológica a favor de elementos detenidos a disposición del Poder Ejecutivo Nacional y que apunta primordialmente a desprestigiar al Gobierno Nacional, se requiere la siguiente información. ${ }^{40}$

Se solicitó la nómina con nombres y apellidos de cada uno de los participantes y la prevención de todo tipo de modalidades disruptivas como la realización de huelgas de hambre o la impresión de materiales de difusión pública. ${ }^{41}$

Cuando la Comisión llegó finalmente a la Argentina el 6 de septiembre de 1979 se instaló en la sede de la OEA en Buenos Aires, en pleno centro metropolitano. Hubo durante dos semanas colas numerosas de familiares en las veredas de la antigua Avenida de Mayo cuyo objetivo era dar lugar a las denuncias y a los reclamos. Esta escena se repitió en distintos provincias del país como Tucumán, Córdoba y Santa Fe, donde la CIDH emplazaba locaciones ad hoc para tomar testimonios y a la vez darles publicidad. Esto dio impulso a que otros familiares que hasta allí no habían presentado denuncias lo hiciesen. Por su parte, el gobierno que en su imaginario unía en un frente único antigubernamental al comunismo internacional, a los militantes de las organizaciones político-militares, a los familiares y a los activistas por los derechos humanos convocó a un festejo en Plaza de Mayo por el triunfo de la selección argentina en el Campeonato Mundial de Fútbol Juvenil en el Japón. Una serie de fotos tomadas el 7 de septiembre de 1979 por el fotoperiodista Guillermo Loiácono confirma la impactante imagen antinómica de quienes pedían por la aparición con vida de sus hijos mientras otros argentinos

\footnotetext{
${ }^{39}$ Fondo DIPBA, Mesa DS, Carpeta Varios, Legajo 134.227. Asunto, Memorando de la delegación DGIPBA La Plata al Señor Director General de Icía., La Plata, 19 de abril de 1979 (nombres tachados en el original)

${ }^{40}$ Ídem.

${ }^{41}$ Fondo DIPBA, Mesa DS, Carpeta Varios, Legajo 13.242. Asunto, Comisión de familiares de desaparecidos y detenidos a disposición del PEN, s/d.
} 
vitoreaban al gobierno con panfletos que contenían la consigna "los argentinos somos derechos y humanos". 42

En todos los puntos del país donde hubo organización cada familia con la ayuda de los organismos de derechos humanos aportó lo necesario para abonar a la solidez de los casos con el propósito de que el gobierno no pudiese recusar su responsabilidad en los hechos denunciados. También las personas detenidas por razones políticas en las cárceles de Villa Devoto, Rawson y Caseros dieron sobradas muestras de su capacidad de coordinación colectiva ante la CIDH. Estas nuevas formas de organización definieron otras iniciativas que a la vez aglutinaron nuevas voluntades de lucha. Fue en esta coyuntura, por ejemplo, que se retomó la distribución de volantes políticos en la vía pública de distintos barrios de la Capital Federal. En efecto, uno de los partes de inteligencia policial relata una actividad que realizó la LADH en las inmediaciones de la calle Gascón y la Avenida Díaz Vélez, en el barrio de Almagro. Allí se dice:

[....] en forma manuscrita con colores morados, negro y rojo sobre papeles de 12 por 18 centímetros de color celeste pregonaban 'Por la inmediata aparición de los 5700 desaparecidos - El nuevo barrio quiere ver pronto a Inés Olleros - Teresa Israel. - Liga Argentina por los Derechos del Hombre. $^{43}$

También los periódicos de la época muestran esta ebullición. Por esos días se recolectaron más de 30.000 firmas y se presentó un petitorio ante el Poder Ejecutivo Nacional con el objetivo de esclarecer las situaciones de reclusión indefinidas de numerosos presos políticos. ${ }^{44}$ Una modalidad que haría punta de lanza en el espacio público y que ya para 1980, tan sólo un año después, pasaría a ser entregado en la misma Casa de Gobierno por medio de movilizaciones de entre quinientas y mil personas. Una cuestión impensable hasta ese momento.

Otros escritos de inteligencia revelan también los pedidos de esclarecimiento de distintas causas que en forma personal o por correspondencia, los familiares, los presos o los organismos de derechos humanos solicitaban a los jueces y a los miembros de la Junta Militar así como también demandas de colaboración a periodistas, artistas e intelectuales. En otros informes se pueden hallar réplicas de presentaciones de habeas corpus individuales y colectivas, cartas a personalidades que residían en el exterior para solicitarles que se pronuncien en contra del gobierno argentino y otros escritos despachados a organismos jurídicos internacionales donde se denunciaba el ejercicio de la violencia estatal contra la sociedad civil.

\footnotetext{
${ }^{42}$ La colección fotográfica perteneciente a Guillermo Loiácono se encuentra en guarda y puede ser consultada en el Archivo Nacional de la Memoria. Secretaría de Derechos Humanos de la Nación Argentina. Ver además La Nación, 7 de septiembre de 1979

${ }^{43}$ Ver Fondo DIPBA, Mesa DS, Carpeta Varios, Legajo 14.431. Asunto Memorando producido por Señor Jefe Delegación Capital Federal (DGIPBA) para información del Señor Director General de Inteligencia, septiembre de 1979.

${ }^{44}$ La Nación, 15 de septiembre de 1979.
} 
En términos generales esta coyuntura se caracterizó por la posibilidad que tuvieron los familiares y los organismos de reunirse, de darle notoriedad a sus reclamos y de fundamentar las violaciones a los derechos humanos llevadas adelante por el Estado argentino ante un organismo internacional veedor. La visibilización de los factores más represivos desplegados por el régimen militar potenció a la vez la prédica y la escucha de otros sectores como fueron las Madres de Plaza de Mayo, que hasta ese momento habían sido acusadas de locas y de mentirosas. Si hubo inicialmente una actitud de resistencia de estos grupos de carácter larvado, luego las acciones se hicieron cada vez más públicas. La llegada de la CIDH dio visibilidad y por esa vía "cobertura" a este accionar, lo que a la vez amplificó a las mismas. Una intensa actividad que, por otro lado, permitió construir redes solidarias entre familiares, presos y organismos de derechos humanos así como la consolidación de sus demandas en el período de transición a la democracia. Las demandas de seguimiento de las agencias de inteligencia de miembros y organismos de derechos humanos se incrementaron sustantivamente en esta etapa justamente porque el poder militar estaba cada vez más deteriorado.

\section{Conclusiones}

La llegada de la CIDH a la Argentina condensó una serie de cambios que erosionaron al régimen militar en los aspectos vinculados con la lógica más cruenta y clandestina de la represión. Los organismos de derechos humanos, los familiares de las personas afectadas por la represión estatal y las personas detenidas en las cárceles por razones políticas vieron en esta visita un estímulo a sus intensos reclamos. El repertorio de acciones se desarrolló además en un marco de colaboración y solidaridad que puso en evidencia que el caso de una familia afectada era el caso de todas. Un enjambre de prácticas que permitió socializar los problemas y que contribuyó a dejar atrás la sensación de impotencia y de soledad.

Las denuncias se constituyeron en un momento fundacional de las formas de organización de las demandas de los organismos, un largo camino que posteriormente se continuó con la actividad de la CONADEP, en los tribunales internacionales, y en toda la pericia adquirida por estos sectores para hallar resquicios de legalidad en su favor. En la esfera nacional, las organizaciones más activas en el ámbito de la defensa de los derechos humanos como la LADH, la APDH, la COMIFADE y el CELS, a los que se suman el Movimiento Ecuménico por los Derechos Humanos (MEDH) y las Madres y Abuelas de Plaza de Mayo, trabajaron en estrecha cooperación con los integrantes de la Comisión ${ }^{45}$. Todos y cada uno de ellos confiaron en que los resultados de esta investigación podrían

\footnotetext{
${ }^{45}$ En la Argentina ha existido históricamente una cultura de denuncia testimonial basada en una detallada descripción de la aplicación de tormentos que la literatura materializó en obras célebres como Operación masacre de Rodolfo Walsh o La Patria fusilada de Paco Urondo. El universo discursivo que atravesó a los Montoneros en el exilio llevó también a que esta organización enfatizara las violaciones a los derechos humanos que se cometían en la Argentina contra los militantes populares. Expresión de ellos es el film "Resistir" realizado en París por Jorge Cedrón en el año 1978, donde Mario Eduardo Firmenich, uno de los máximos dirigentes de esta organización, denuncia el salvajismo de la tortura militar.
} 
ofrecerles a las víctimas del terrorismo de Estado elementos para conjurar la represión en el país.

La puesta en debate de las violaciones a los derechos humanos les permitió a estos sectores a la vez dinamizar un cúmulo de acciones cada vez más notables en la esfera pública y en un contexto donde a nivel internacional se rechazaba la omnipotencia de las dictaduras de seguridad del Cono Sur. La visita de este organismo operó como un catalizador que modificó la ecuación en torno a lo que hasta allí el Estado había intentado ocultar. A pesar de que el gobierno intentó morigerar el impacto del informe final de la CIDH y prohibir su difusión, el conjunto de estos elementos, largamente aquí analizados, favoreció la pérdida de legitimidad del régimen militar en la sociedad civil. En materia de derechos humanos la balanza se inclinó cada vez más en favor de quienes denunciaban su quebrantamiento. Y fue a partir de este cambio de situación que los distintos protagonistas del escenario político comenzaron a disputarse el sentido asignado a la "guerra contra la subversión": una cuestión que estaba provocando importantes cambios en la agenda política y que sería decisiva en los albores de la transición al Estado de derecho en el año 1983.

\section{Referencias Bibliográficas}

Águila, Gabriela, "Las tramas represivas: continuidades y discontinuidades en un estudio de caso. La Dirección General de Informaciones de la Provincia de Santa Fe, 1966-1991”, Sociohistórica, n 31, 2013, 1-26.

Ayala, Mario, "La formación de comités y redes de lucha contra la dictadura militar de los exiliados argentinos en Venezuela: interacciones locales, regionales y transnacionales (1976-1981), El@tina, Vol. 12, No 46, 2014, http://publicaciones.sociales.uba.ar/index.php/elatina

Barreneche, Osvaldo, "Manejo metodológico de las fuentes documentales y los archivos policiales. El caso de la Policía de la Provincia de Buenos Aires", Revista Electrónica de Fuentes y Archivos del Centro de Estudios Históricos "Prof. Carlos S. A. Segreti", No 1, 2010, 1-17.

Basualdo, Victoria, “Introducción”, Colección 8: Petroquímica Sudamericana. Hilandería Olmos. Mafissa (1963-1991), Comisión Provincial por la Memoria, CD-ROM, 2009.

Caimari, Lila, "En guerra contra el hampa. Policía y Modernización tecnológica en el Buenos Aires de los años treinta", Bohoslavsky, Ernesto, Caimari, Lila y Schettini, Cristiana (org.), La policía en perspectiva histórica. Argentina y Brasil (del siglo XIX a la actualidad), CD-ROM, Buenos Aires, 2009.

Canelo, Paula, El proceso en su laberinto. La interna militar de Videla a Bignone, Prometeo, Buenos Aires, 2008.

Casola, Natalia, El PC argentino y la dictadura militar. Militancia, estrategia política y represión estatal, Imago Mundi, Buenos Aires, 2015.

Casola, Natalia “ $i L o s$ comunistas no somos subversivos!”. El PC y la dictadura militar argentina (1976-1983)", en Revista Archivos del Movimiento Obrero y la Izquierda, № 2, 2013, 133-156.

Casola, Natalia, "Cuando lo "nuevo" es tan "viejo" como "nuevo" lo "viejo". El movimiento de derechos humanos durante la última dictadura militar en Argentina. El papel del Partido Comunista de Argentina y la Liga Argentina por los Derechos del Hombre (1976-1983)", en História Oral, V. $13, \mathrm{~N}^{\circ} 2,2010,137-155$.

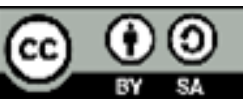


Chama, Mauricio, "La defensa de presos políticos a comienzos de los '70: ejercicio profesional, derecho y política", Cuadernos de antropología social. $N^{\circ}$. 32, 2010, 195-217.

D’Antonio, Débora y Eidelman, Ariel, "El sistema penitenciario y los presos políticos durante la configuración de una nueva estrategia represiva del Estado argentino (1966-1976)", Revista Iberoamericana, vol. X, No 40, 2010, 93-111.

Da Silva, Catela, "Etnografía de los archivos de la represión en la Argentina", Franco, Marina y Levín, Florencia (comps.), Historia reciente. Perspectiva y desafíos para un campo en construcción, Paidós, Buenos Aires, 2007, 183-220.

Eidelman, Ariel. "El PRT-ERP y la lucha por la libertad de los presos políticos, 1971- 1973", Sociohistórica, $\mathrm{N}^{\mathrm{o}} 25,2009,13-39$.

Franco, Marina, El exilio. Argentinos en Francia durante la dictadura, Siglo XXI, Buenos Aires, 2008.

Franco, Marina, "En busca del eslabón perdido: reflexiones sobre la represión estatal de la última dictadura militar", Revista Estudios, $N^{\mathrm{o}} 25,2011,31-45$.

Funes, Patricia, "Secretos, confidenciales y reservados. Los registros de las dictaduras en la Argentina. El Archivo de la Dirección de Inteligencia de la Policía de la provincia de Buenos Aires", Quiroga, Hugo y Tcach, César (comps.), Argentina 1976-2006. Entre la sombra de la dictadura y el futuro de la democracia, HomoSapiens ediciones, Rosario, 2006, 199-232.

Funes, Patricia, "Desarchivar lo archivado. Hermenéutica y censura sobre las ciencias sociales latinoamericanas", Íconos No 30, 2008, 27-39.

Ghigliani, Pablo, "Archivos policiales e historia social del trabajo (1957-1976), VII Jornadas de Sociología de la UNLP, La Plata, diciembre de 2012, http://www.memoria.fahce.unlp.edu.ar/trab_eventos/ev.1975/ev.1975.pdf

González Quintana, Antonio, "Los Archivos de la represión: balance y perspectivas", Comma. Revista Internacional de Archivos, № 2, 2004, 59-74.

Green, James, Apesar de vocês: a oposicào a ditadura militar nos Estado Unidos, 1964-1985, Companhia das Letras, Sào Paulo, 2009.

Jelin, Elizabeth, "Introducción. Gestión política, gestión administrativa y gestión histórica: ocultamientos y descubrimientos de los archivos de la represión", Da Silva Catela, Ludmila y Jelin, Elizabeth (comps.) Los archivos de la represión: documentos, memoria y verdad, Madrid, Siglo Veintiuno, 2002, 1-12.

Jensen, Silvina, Los Exiliados. La lucha por los derechos humanos durante la dictadura, Sudamericana, Buenos Aires, 2010.

Kahan, Emmanuel, Unos pocos peligros sensatos. La Dirección de Inteligencia de la Policía de la Provincia de Buenos Aires frente a las instituciones judías de la ciudad de La Plata, Tesis de Maestría, Universidad Nacional de La Plata, 2007.

Kahan, Emmanuel, “¿Qué represión, qué memoria? El archivo de la represión de la DIPBA: Problemas y perspectivas", Question, vol. $\mathrm{N}^{\mathrm{o}} 1, \quad \mathrm{~N}^{\mathrm{o}}$. 16, 2010, 1-10, http://perio.unlp.edu.ar/ojs/index.php/question/article/view/459

Kalmanowiecki, Laura, "Origins and Applications of Political Policing in Argentina", Latin American Perspectivas, Vol. 27, No 2, marzo 2000, 36-56.

Manzano, Valeria, "Sex, Gender and the Making of the 'Enemy Within' in Cold War Argentina", Journal of Latin American Studies, vol. № 47, № 1, 2014, 1-29.

Olmo, Darío, "Reconstruir desde restos y fragmentos. El uso de archivos policiales en la antropología forense en la Argentina", Da Silva Catela, Ludmila y Jelin, Elizabeth (comps.), Los archivos de la represión: documentos, memoria y verdad, op. cit, 179-194.

Sozzo, Máximo, (dir.) Policía, violencia, democracia. Ensayos sociológicos, Ediciones UNL, Universidad Nacional del Litoral, Santa Fe, 2005. 
Waldamnn, Peter, "Represión Estatal y Paraestatal en Latinoamérica", Revista América Latina Hoy, 2 época, $N^{\circ} 19,1995,21-28$.

Yankelevich, Pablo (comp.), Represión y destierro. Itinerarios del exilio argentino, Al Margen, La Plata, 2004.

Yankelevich, Pablo y Jensen, Silvina (comps.), Exilios. Destinos y experiencias bajo la dictadura militar, Del Zorzal, Buenos Aires, 2007.

Fuentes periódicas

Clarín, septiembre de 1979

Página 12, agosto de 1999

Fuentes documentales

Misión de Amnistía Internacional a la República Argentina, 6-15 noviembre de 1976, Anmnesty International Publications, Londres, 1977.

Informe sobre la situación de los derechos humanos en Argentina, aprobado por la Comisión Interamericana de los Derechos Humanos en el 49. ${ }^{\circ}$ Período de Sesiones, 1980.

Fuentes del archivo de la ex DIPBA

Fondo DIPBA, Mesa Delincuente Subversivo (DS), Legajo 134.227, asunto: "Plan de los familiares de los presos y desaparecidos ante la Comisión Permanente por los Derechos Humanos, del Batallón de Inteligencia 601 para SIA, SIN, SIPNA, DIPBA, S/FED, DIGN, SIDE, GT 2, GT 3, GT 4 y GT 5, s/d".

Fondo DIPBA, Mesa Delincuente Subversivo (DS), Legajo 134.227, asunto: “Mensaje N. ${ }^{\circ} 07013$ de Batallón de Inteligencia 601, s/d de marzo de 1979".

Fondo DIPBA, Mesa Delincuente Subversivo (DS), Legajo 134.227, asunto: "Memo del Jefe Delegación DGIPBA Tigre para información del señor Director General Inteligencia, La Plata, s/d de febrero de 1979".

Fondo DIPBA, Mesa Delincuente Subversivo (DS), Legajo 134.227, asunto "Memorando del Jefe de la Seccional Regional DGIPBA No 1 de Morón al Señor Director General de Icía., La Plata, 6 de febrero de 1979".

Fondo DIPBA, Mesa Delincuente Subversivo (DS), Legajo 134.227, asunto "Nota desde la Delegación DGIPBA, Mar del Plata; al Señor Director General de Inteligencia, La Plata, 16 de febrero de 1979".

Fondo DIPBA, Mesa Delincuente Subversivo (DS), Legajo 134.227, asunto "Memorando del Jefe de la Delegación Regional DGIPBA San Martín al Señor Director General de Icía., La Plata, 6 de febrero de 1979".

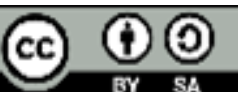


Fondo DIPBA, Mesa Delincuente Subversivo (DS), Legajo 14.431, asunto "Memorando producido por Señor Jefe Delegación Capital Federal (DGIPBA) para información del Señor Director General de Inteligencia, s/d septiembre de 1979”.

Fondo DIPBA, Mesa Delincuente Subversivo (DS), Legajo 134.227, asunto "Memorando del Jefe de la Seccional Regional DGIPBA Bahía Blanca al Señor Director General de Icía., La Plata, 14 de marzo de 1979".

Fondo DIPBA, Mesa Delincuente Subversivo (DS), Legajo 134.227, asunto, "Memorando de la delegación DGIPBA La Plata al Señor Director General de Icía., La Plata, 19 de abril de 1979”.

Fondo DIPBA, Mesa Delincuente Subversivo (DS), Legajo 134.227, asunto, "Memorando del Jefe de la delegación DGIPBA Capital Federal con destino al Señor Director General de Icía., La Plata, 23 de mayo de 1979".

Fondo DIPBA, Mesa Delincuente Subversivo (DS), Legajo 13.242, asunto, "Comisión de familiares de desaparecidos y detenidos a disposición del PEN, por DGIPBA para información del Señor Jefe Delegación La Plata de la Policía Federal, 2 de abril de 1979”.

Fondo DIPBA, Mesa Delincuente Subversivo (DS), Legajo 13.242, asunto, "Memorando producido por DGIPBA para información del Señor Jefe Delegación La Plata de la Policía Federal, 2 de abril de 1979".

\section{Fuentes fotográficas}

Colección Guillermo Loiácono, Archivo Nacional de la Memoria, Secretaría de Derechos Humanos de la Nación Argentina.

Fuentes audiovisuales

Resistir, Jorge Cedrón, París, 1978.

Páginas webs consultadas

http://imagendiplomatica.com

http://www.comisionporlamemoria.org/timerman/

http://www.saij.gob.ar/docs-f/ediciones/libros/Batallon_inteligencia_601.pdf 